\title{
10. Eco-Ethics as the Foundation of Conservation
}

\author{
HENRYK SKOLIMOWSKI \\ University of Michigan, \\ Ann Arbor, \\ MI 48109, USA
}

\section{Summary}

Environmental ethics must be distinguished from ecological ethics. While the former concerns itself with the appropriate management of natural resources and is often guided by cost-benefit analysis, the latter (ecological ethics) is much broader as it spells out the relationships between man and nature; and also analyses those attributes of man which can make him an ecological animal. Eco-values are based on the recognition of intrinsic values of which reverence for life is one, and perhaps the most important one. Without recognizing some intrinsic values we do not have a basis which is sufficiently universal and comprehensive to talk either of environmental ethics or eco-ethics. The values of eco-ethics are an inherent part of ecological thinking.

\section{Without Values Our Thinking is Incomplete}

Among the resources we possess and must cultivate is thinking. In many cultures, particularly traditional cultures, there is a deep understanding that right thinking leads to right action. The idea of right thinking of course is a category much larger than specialized thinking within any specific domain, be it fishery or forest conservation. Right conservationist strategies, let us emphasize, are the ones that would benefit all human kind. The idea of 'conservation', the idea of 'strategy' and the idea of 'benefit for all humankind' are all value terms. Pure objective science has little use for such concepts as 'conservation', 'benefit to all', 'survival value', for these are categories outside the content of objective science, and they are outside so-called 'cognitive content'. These categories are immensely important to us and our well-being in the short run and in the long run. Thus the entire premise of right conservation on the global scale is steeped in values. Simply, the conservation strategy is a value programme. We do not deny that it is also a scientific programme. We need to know in great detail what we are doing, but at the same time we must not forget for a moment why we are doing what we are doing. The scientific component of conservation strategies and the value component do not clash with each other, but complement each other.

Since the whole project is in the service of values, we cripple our thinking by denying values. This is an important point. I am not saying that we should tolerate values as an appendage to our objective thinking, but rather that the integrity and validity of our thinking depends on our capacity to integrate values into our thinking; and conversely, on our capacity to integrate analytical thinking into the framework of sustainable values.

In so many traditional societies, the Buddhist especially, there is a clear awareness that right thinking, and right attitudes lead to right action. I will let the poet T. S. Eliot make a main point for me:

A wrong attitude towards nature implies somewhere, a wrong attitude toward God, and the consequence is an inevitable doom.

\section{Conservation is an Ethical Act}

When excessive specialization claims larger and larger parts of our minds, conservationists may be the only true guardians of the whole earth. Insofar as they are part of the scientific community, they are under the strictures of the accepted methodological principles. However, insofar as they are the true guardians of the whole earth, they may have to overcome and transcend some of these strictures.

What is conservation? Conservation is an act of caring to the point of fighting for what you consider important to preserve-even against considerable odds. When the world is shrinking and the earth is devoured by expanding populations and expanding concrete surfaces, how can we establish and maintain a right and rational strategy for preservation? The answer is not by treating habitats we wish to preserve, as choice pieces of property, but by regarding them as something of intrinsic value.

We must justify eco-habitats to be of intrinsic value, and not as pieces of commodity to be 
evaluated by market strategies, by realizing that conservation is an ethical act, which is based on the premise that we are preserving the richness and uniqueness of life itself.

This of course assumes the recognition of the unity of life, of which we are a part. This unity of life must be viewed not in the trivial sense, as paying lip service to the idea that we are all interconnected, but in a deeper sense, by acknowledging reverence for all life, and by making our stewardship of life a principle of paramount importance.

The guardianship of the heritage of life is a much larger proposition than the maintenance of scientific objectivity. This we have to acknowledge quite clearly, and yet we find that we have an almost moral obligation to maintain the principle of scientific objectivity. This alleged moral obligation must be carefully examined; we want to pursue a rational path; we don't merely want to adhere to a dogma.

The reconciliation of these two seemingly incompatible ethics: of objectivity and of caring, though difficult, is both necessary and possible. We must simply look at the criteria of objectivity for different kinds of systems. The objectivity of the very small (sub-atomic particles) and the very large (galaxies and black holes) are not the same thing. The objectivity of the very simple and the objectivity of the very complex are again governed by different criteria. The objectivity of systems without a time dimension and of systems evolving in time are different again. We must therefore not apply one kind of objectivity (characteristic of simple timeless systems, which we analyse in chemistry for instance) to all other systems: of different complexity, different dimensions, of enormous number of variables, and in which time is a most important factor.

When properly analysed, we shall find as many different types of objectivity as there are disciplines examining different aspects of life or of the universe. An objective way of looking at the life process, when we attempt to understand life as life, is one which must enable us to understand the diversity of the forms of life within the unity of all life. This act of deeper understanding is based on the faculty of empathy, or identification with other forms of life, which is, at the same time, an act of caring. This is a moral act, in a sense an act of participation in life. Therefore, forget about Jacques Monod (1971) and his opus Chance and Necessity, for what he promotes is not understanding life in its evolution, but reducing life to its chemical components. Yes, we shall not deny that there is some light that comes from the study of molecular structures of living organisms. But there is a different principle of objectivity in action when we examine molecular structures in the laboratory, on the one hand, and when we examine life in evolution, on the other hand.

I have deliberately chosen the case of the objectivity of chemistry, as perhaps the most confining one, for physics nowadays is quite a different matter. Already with Einstein (relativity), Heisenberg (uncertainty) and Bohr (quantum theory) enormous difficulties had arisen in applying the criteria of objectivity characteristic for the Newtonian system. In recent years, the New Physics has been bursting in new and unexpected directions, to the point that the principle of objectivity (in the old-fashioned Newtonian sense) is considered an antiquated thing of the past.

The proponents of the New Physics are telling us that we live and think in the participatory universe. We cannot be objective, and never are objective, in the strict old-fashioned sense (even in molecular biology). We are always co-creators participators. (Witness in this context the writings of John Archibold Wheeler.)

The new concept of objectivity, if we are still to preserve the term, is one of the participatory process, and this concept is excellently suited to our new ethics of conservation. Conservation as an ethical act is now well justified by the strategies and methodologies of the New Physics and, especially, its concept of participation.

\section{"Man Did Not Weave a Web of Life, He is Merely a Strand in it. Whatever He Does to the Web, He Does to Himself."}

Before I attempt to outline some principles specific to eco-ethics, let me share with you a couple of fragments of the great speech of the Red Indian Chief Seattle, delivered in 1854. In this speech, in a poetic and metaphorical way, he captures the spirit of eco-ethics. It is this spirit that we must bear in mind when we contemplate conservation as an ethical act, and other principles of eco-ethics. Chief Seattle said:

"The Great Chief in Washington sends word that he wishes to buy our land...

How can you buy or sell the sky, the warmth of the land? The idea is strange to us. If we do not own the freshness of the air and the sparkle of the water, how can you buy them?

Every part of this earth is sacred to my people. Every shining pine needle, every sandy shore, every mist in the dark woods, every clearing and humming insect is holy in the memory and experience of my people. The sap which courses through the trees carries the memories of the red man... 
Teach your children what we have taught our children: that the earth is our mother. Whatever befalls the earth befalls the sons of the earth. If men spit upon the ground they spit upon themselves.

This we know. The earth does not belong to men; man belongs to earth. This we know. All things are connected like the blood which unites one family. All things are connected. Whatever befalls the earth befalls the sons of the earth. Man did not weave the web of life, he is merely a strand in it. Whatever he does to the web, he does to himself."

Conservation Work is About Responsibility. We Abrogate our Responsibility if We Know The Truth and Do Not Convey it to Others

We would not have designed all the various conservation strategies, if we did not feel responsible for the survival and well-being of ecohabitats and whole environments. Responsibility is a moral category. No scientific description of any habitat can make us responsible for it unless and until we feel responsible for it. Feeling and being responsible for environments and natural resources is being responsible for the world larger than oneself and also being responsible to future generations: of humans and non-humans as well. Our responsibility is effective if we inspire others to be responsible. Responsibility is contagious, for it has a moral force behind it.

However, we have a problem here. Our culture, and by this I mean western culture, seems to discourage us from acknowledging values as a legitimate part of our scientific and cognitive endeavours. Thus in spite of our better knowl edge we often deny or suppress value considerations though we deep down know of their importance. This is the result of the positivist philosophy that has crept into our academia and our thinking and which tells us that values do not belong to the realm of rational cognition and must be therefore eliminated from man's rational discourse, which is of course nonsense when you come to reflect upon it. Yet the atrophy of values is a fact. We are all-constrained by the positivist straitjacket.

The situation has been incisively summarized by a distinguished Norwegian philosopher, Arne Naess, who wrote in a letter to me:

"People in nature management and in important institutions having to do with environment and lifestyles remain silent for tactical reasons: they are afraid to seem too idealistic, to take too long a time and place perspective, to appear romantic-not tough enough. If they confessed what they value at hear, others would do the same."
I think Arne Naess has hit the nail upon the head and identified one of the important reasons why so many conservationists keep silent. Many of them would like to say to others: "Awake, don't you see that this tough-mindedness, this process of reducing everything to economic commodities is in fact bloody-mindedness. What we are at present pursuing is not realism but the worst kind of fiction which is leading us to our own extinction." This is what so many of us think. But if so, then we shall have to break the conspiracy of silence, for this conspiracy does not serve any form of realism. Instead it is aiding and abetting a destructive fiction. Let us also reflect that if to know the truth, and stand by it, is to appear romantic, then there is something wrong with the whole structure of society.

The responsibility for environments and for their right conservation is our moral obligation if we are to leave behind any meaningful heritage for future generations; and it is our responsibility also to instill the sense of responsibility in each other. The World Charter for Nature (Point 8), proposed at the UN in June 1980 is in a similar vein.

"Man must acquire the knowledge to maintain and enhance his ability to use resources in a manner which benefits present and future generations without lasting injury to nature. Man can be in harmony with nature if the human community acts as a steward for nature in the interests of future generations."

Emil Salim, in his excellent address Conservation and Development delivered to the Royal Institution in London in 1981, developed this theme still further when he said:

"Our aim is not just mere survival; our aim is the type of global conditions where man-all men-can live in dignity in the environment of his choice, conditions where man can life in harmony with his fellow man, in harmony with his environment and in harmony with God, the source of all life.

It is abundantly clear even today that the environment is indivisible; that the degradation of the environment in one location in the end affects the environmental quality of the entire globe. The welfare of the entire globe is therefore the responsibility of people everywhere, regardless of the specific location where environmental degradation is actually taking place."

Cost-Benefit Analysis is Insufficient as the Basis for Long-Range Conservation Strategies, and is in the Service of Myopic Values

The most effective strategies for conservation and maintenance of natural resources are not through mere economic calculations, but through 
the promotion of right eco-values. This point may appear debatable, at least in some quarters in which cost-benefit analysis is elevated to a supreme criterion. Let us therefore examine the situation more closely. The cost-benefit analysis itself is an expression of a value judgement for it tells us that we should value economic renumeration over everything else. This is an important point to remember: we are encouraged to abandon traditional values in favour of the economic value, in favour of reaping profit in the short run. There is clearly a value judgement behind seemingly objective cost-benefit analysis. As conservationists and comprehensive thinkers dealing with global strategies, we must resist this kind of subversion of our thinking based on a value which - as we have seen over and again is so inadequate in the long run. If we are so clever that we can exploit everything to our advantage, then we must not be so stupid as to cut off the branch on which we sit.

Yet, development is important, particularly for the Third World nations. Incidentally, I often have the feeling that the idea of development has been made into a fetish in the developing countries. What 'progress' signified in the West some 20 years ago-the sacred cow beyond criticism and shadow of any doubt - development came to signify in the Third World nations. Be it as it may, we have to find a way of reconciling conservation with development. Now, let us reflect and realize that the very formulation of our dilemma is slanted in favour of development. For reconciling conservation with development almost invariably means (even in the boundaries of eco-development; though I may be mistaken about that) constraining conservation to the demands of development.

We should have the courage and wisdom to look at the total equation, at the whole panorama of man's culture, including his spiritual needs. What I specifically mean is beautifully rendered in the book by Colin Turnbull (1962) in which the lonely African thus speaks:

"I have tried hard to understand the white man and his ways, but I can see only harm. What happiness have they brought us? They have given us a road we did not need, a road that brings more and more foreigners and enemies into our midst, causing trouble, making our women unclean, forcing us to a way of life that is not ours, planting crops we do not want, doing slave's work. At least the BaNgwana left us our beliefs, but the white man even wants to steal these from us. He sends us missions to destroy our belief and to teach our children to recite fine-sounding words: but they are words we believe in anyway, most of them. And we live according to our beliefs, which is more than the white man does".
Is the lonely African with his values going to be melted in the melting pot of one homogenized culture?

In this context let me suggest that all ethics have always been in the service of conservation and preservation. All ethics wish to preserve and conserve the sanctity of the human being, his wholeness, his integrity. The virtues that various systems of ethics advocate and wish us to uphold always serve some programme of conservation. Here therefore is another argument for our earlier claim that conservation should be seen as an ethical principle. For all ethic is conservation; and all conservation is ethic.

Every Form of Life is Unique, Warranting Respect Regardless of its Present Worth to Man

How do we preserve the integrity of the people still adhering to traditional life-styles in our times of change and development? Perhaps by maintaining that not only every culture is of intrinsic value and should be spared but also that every form of life is unique, warranting respect, regardless of its present worth to man. This principle is so expressed in Point 8 of the UN World Charter for Nature, which I have already mentioned.

Now, in order to treat every form of life as unique, and as a value in itself, we must develop certain attitudes, certain frames of mind, in short, values specific to eco-ethics which would inspire right behaviour and make us take seriously our intrinsic evaluations of eco-habitats. When we look deeper into the attitudes that are required of us to treat every from of life as unique; when we inquire what modes of thinking would be required to respond adequately to the demands of the heritage of whole life, then we must come to the conclusion that no form of objective thinking will ever suffice. Instead we must develop and implement reverence for life.

Reverence for Life is Both an Ecological Value and an Important Principle of Conservationist Strategies, for Without Endorsing it, our Defence of Living Habitats will Hang in Thin Air

Reverence for life is not you and me talking about it. If it is to become a reality we must change the modes of our thinking. We must develop what I should like to term as reverential thinking, which is quite a different kind of thinking from one that is thrust upon us in present schools and academia. The 'official' thinking is an objective one which often goes against the grain 
of reverential thinking and the principle of reverence of life itself.

To think reverentially is first of all to recognize human life as an intrinsic value; is it to recognize love as an essential and indispensable modality of human existence; is it to recognize creative thinking as an inalienable part of human nature; is it to recognize joy as an inherent part of daily living; is it to recognize the brotherhood of all beings as the basis of our epistemological paradigm.

Aldo Leopold (1949) was clearly anticipating this new ethic, which he called a land ethic, in his memorable book $A$ Sand County Almanac. He claimed:

"All ethics so far evolved rest upon a single premise: that the individual is a member of a community of interdependent parts. His instincts prompt him to compete for his place in that community, but his ethics prompt him to cooperate. The land ethic simply enlarges the boundaries of the community to include soils, waters, plants, and animals, or collectively, the land."

The enlargement of ethic so that it includes as part of the global eco-community soils and waters, plants and animals, rocks and other beings, brings us to the idea of eco-justice. This idea has been of late pursued by churches which are becoming more and more ecologically aware. There are two simultaneous movements converging; the churches slowly enlarge their conscience to include justice for all beings in this universe; so that we read in one of the pamphlets, on ecojustice (produced by American Baptist National Ministries), that 'Humanity and nature can come together in eco-justice'. The pamphlet goes on to explain that eco-justice means joining together concerns for ecology and justice. It expresses the age-old dream that 'Earth shall be fair, and all her people wise'. The other movement is the ecology movement which is slowly gravitating toward the idea that we shall need a spiritual basis to make an ultimate sense of our ecological concerns. An eco-theology is thus in the making.

What reverence for life means in terms of our thinking, perception and attitudes toward all beings is beautifully expressed in the passages of the Chief Seattle I have already quoted. Traditional life-styles of many cultures provide eloquent evidence that reverential thinking is not only possible but has been practiced on a large scale. The strength and sustainability of many traditional cultures and traditional life-styles consisted precisely in enshrining the attitude of reverence for life as a modus of daily life. In brief, reverence for life, as an essential value of eco- ethics and eco-culture, must not be seen as a luxury but as an endorsement of a way of looking at life.

Our Evolutionary Heritage is a Value, and Evolution Can be Used as the Criterion as to Which Forms of Life are More Valuable than Others: the More Accomplished a Creation of Evolution, the More Worthy it is of Preservation

Organisms not only live in large habitats but they are also a product of evolution. Evolution itself is a value. It is within the matrix of evolution that everything happens. In both human realities and ecological habitats there are always conflicts between different demands of life. Reverence for life should be maintained as much as possible. But we cannot extend it to all living forms all the time. In times of conflict how should we decide which form of life is more important, if we claim that each form of life is unique? I suggest that we use the criterion of evolution: the more exquisite the form and the more accomplished the product of evolution it represents, the more worthy it is of preserving. In my book Eco-Philosophy: Designing New Tactics for Living (Skolimowski, 1981) I have outlined the evolutionary imperative and its values. If we accept evolution as continually transcending itself, in other words as emergent; and if we accept ourselves as a part of the evolutionary process, the question is, what values can we extract from the evolutionary process and how can these values, if judiciously applied, shape our attitude and behaviour? I suggest that the following precepts can be extricated from intelligent reading of evolution:

- behave in such a way as to preserve and enhance the unfolding of evolution and all its riches;

- behave in such a way as to preserve and enhance life, which is a necessary condition for carrying on evolution;

- behave in such a way as to preserve and enhance the ecosystem, which is a necessary condition for further enhancement of life and consciousness;

- behave in such a way as to preserve and enhance the capacities which are the highest developed form of the evolved universe: consciousness, creativeness, compassion;

- behave in such a way as to preserve and enhance human life which is the vessel in which the most precious achievements of evolution are contained. 
These five characteristics of the evolutionary imperative are only variations on the same theme. They all follow from the first formulation. However, the articulation of the first formulation makes us aware and gives us a guidance on how to act in times of conflict. From the standpoint of the evolutionary imperative, if we have to take the life of a human being or a mosquito, we should not hesitate but take the life of a mosquito - for it is a far less accomplished product of evolution. We have always known this by instinct. The evolutionary imperative justifies as a right moral principle that which we have acted upon through our instinct.

My evolutionary imperative has been challenged by deep ecology proponents as heedlessly anthropocentric; indeed as spelling out a new version of the old-fashioned concept of the superiority of man over all other beings, and as giving a carte blanche for the exploitation of other beings for the benefit of man. Yet, I wish to submit that this old-fashioned anthropocentrism cannot be found in my imperative. What can be found in my imperative is an awareness that ethical choices are choices of values, and when I am faced with a choice: whether to take the life of a mosquito or a life of a human being, I choose (on the basis of the evolutionary criterion) the life of a mosquito. What other criteria are there? Total egalitarianism, according to which every form of being has an absolutely equal right, is a nonsense from the human point of view, and I must emphasize - that this is the only point of view we have: human, even when we wish to argue against this point! Total egalitarianism is also against the modus operandi of nature; and of the whole of evolution - as we understand it. Do the proponents of deep ecology wish to say that they know better than nature and evolution? And what is their special mandate that enables them to cast out all other views which disagree with theirs-when the subject is so intricate, complex and difficult? Moreover, from the standpoint of the Third World Nations, the gospel of return to original natural conditions of the hunter-gatherer societies, whereby we shall have to eliminate some $80 \%$ of the world's population-this concept means a systematic genocide. For where do we start 'eliminating' the overabundant populations (may I ask deep ecology people) if not from so-called overpopulated countries? Thus on one interpretation deep ecology is spelling out a version of population fascism; unintended by deep ecology people no doubt, but embedded in some premises of deep ecology nevertheless.
Self-reliance of Individuals, Nations and Cultures is an Ethical Imperative so that the Idea of Responsibility (of Individuals and Nations) does not Become Meaningless

Eco-justice demands that we not only assume our responsibilities, but also that we have the scope and the possibility to do so. Self-reliance, the capacity to be your own master, thus appears to be one of the values indispensable for ecojustice. This refers to the self-reliance of individuals, who must not be dwarfed by the machine, bureaucracy, or some other forces that crush the will of individuals and make mockery of their responsibility for themselves and their ecohabitats; and this also refers to the self-reliance of nations which must be able to sustain themselves and not be so dependent on and so determined by other nations that the will and interests of these other nations will make mockery of self-management and indeed the sovereignty of dependent nations.

Self-reliance of individuals and nations is one side of the coin; ecological diversity is the other side of this coin. In order to do justice to the variety of lands, climates, circumstances and traditions we have to cultivate diversity in ecological, agricultural (as well as cultural) terms. For this diversity is the basis of self-reliance; and vice versa; self-reliance in so vastly varied circumstances of our globe, and within different traditions simply means encouraging and maintaining diversity. Diversity means heterogeneity; means the opposite of homogeneity. Homogeneity profits central economies, high-tech homogeneity. Heterogeneity profits local people; enables them to be self-reliant; ultimately enables them to be responsible and good stewards.

We therefore have a cluster of three concepts: self-reliance, diversity and heterogeneity which do not seem at the first sight to belong to the realm of ethics, and yet on a closer inspection have clearly ethical implications; are in fact a part of eco-ethic.

To put the matter in a crude and simplified manner: it is immoral to allow homogeneity to prevail.

\section{Conclusion}

The International Union for the Conservation of Nature and Natural Resources, especially its Commision on Ecology, should be lauded and applauded for taking the initiative to develop eco-culture and eco-ethic. This initiative is very timely and very important as can be witnessed by signs coming from various quarters. 
Already in the early 1970s the Polish writer Alexandrowicz wrote a penetrating essay entitled Ecological Conscience; and this was a statement coming from Communist Poland. In the late 1970 s and early 1980s the awareness that our ethic must be ecologically based has been emerging from various quarters, among which the churches seem to be taking more and more decisive initiative-calling not only for ecojustice ('Humanity and nature can come together in eco-justice'), but also calling for enacting the 11 th Commandment. Thus we read in the essay by Vincent Rossi entitled: Toward an Ethic of Ecology that:

"The earth is the Lord's and the fullness thereof: Thou shall not despoil the earth, nor destroy the life thereon."

This statement comes from the organization calling itself (interestingly enough!) The Eleventh Commandment Fellowship, and is based in San Francisco.

From other quarters we have heard powerful, if at times lonely, voices of Murray Bookchin, who tied his ecological ethic to an anarchist philosophy; and of Thomas Berry, who is more Teilhardian in his inspiration (Teilhard de Chardin, 1959). Of course there is a legion of others with various degrees of commitment and different emphases. Among them the people around the Jour nal for Environmental Ethics, as well as the group concerned with deep ecology, whose chief inspiration is John Muir, should be particularly mentioned.

The time for eco-ethics has arrived. It may be said without exaggeration that unless we develop and implement eco-ethics as based on some intrinsic values, our work as conservationists will be superficial and ineffective. It is to be hoped that working conservationists, members of the Commission on Ecology in particular, will not shy from value considerations, but will consciously and deliberately include them in their work because these values are the hidden springs of our action and thought.

\section{References}

Disch, R. (1970) The Ecological Conscience (Values of survival), Prentice-Hall, Englewood Cliffs, NJ.

Leopold, A. (1949) A Sand County Almanac-with essays on conservation from Round River, Ballantine Books, New York.

Monod, J. (1971) Chance and Necessity.

Salim, E. (1981) Conservation and Development, Second World Conservation Lecture, WWF, London.

Schweitzer, A. (1949) Out of My Life and Thought, A Mentor Book, New York.

Skolimowski, H. (1981) Eco-Philosophy: Designing new tactics for living, Marion Boyars, London.

Teilhard de Chardin, P. (1959) The Phenomenon of Man, Collins, London.

Turnbull, C. (1962) The Lonely African, Simon and Schuster, New York. 